Cintia Almeida da Silva Santos

Universidade Federal de São Carlos (UFSCar), São Carlos, São Paulo, SP, Brasil.

Samara Pereira Tedeschi

Universidade Federal de São Carlos (UFSCar), São Carlos, São Paulo, SP, Brasil.

Wanda Aparecida Machado Hoffmann Universidade Federal de São Carlos (UFSCar), São Carlos, São Paulo, SP, Brasil.

\section{A comunicação pública da ciência e as relações com as expertises}

\section{Public communication of science and the relationship with the expertises}

\author{
La comunicación pública \\ de la ciencia y las relaciones \\ con los peritajes
}




\section{RESUMO}

Objetivo desta pesquisa é analisar as relações da comunicação pública da ciência e as relações com as expertises. A metodologia utilizada compreendeu um levantamento e análise do referencial teórico sobre o tema, aliado à realização de uma pesquisa empírica no Instituto Federal de São Paulo, por meio da análise feita em um boletim institucional que se encontra com publicação suspensa. Considera-se que, após a análise e discussões efetuadas, a publicação é um veículo importante para a comunicação pública da ciência, por se tratar de um mecanismo de integração entre categorias e não de segregação.

Palavras-chave: Comunicação Pública da Ciência. Expertises. Sociedade.

\section{ABSTRACT}

The objective of this paper is to analyze the relationships of public communication of science and relations with expertises. The methodology included a survey and analysis of the theoretical ally conducting empirical research at the Federal Institute of São Paulo, through analysis in an institutional newsletter that is with suspended publication. It is considered that the publication is an important vehicle for public communication of science, because it is a mechanism of integration between categories and not segregation.

Key-words: Public Communication of Science. Expertise. Society.

\section{RESUMEN}

El objetivo de esta investigación es analizar las relaciones de comunicación pública de la ciencia y las relaciones con los peritajes. La metodología comprendido en un estudio y análisis del marco teórico en el aliado objeto la realización de la investigación empírica en el Instituto Federal de São Paulo, a través del análisis de un boletín institucional que es a la publicación suspendida. Se considera que tras el análisis y las discusiones llevadas a cabo, la publicación es un importante vehículo para la comunicación pública de la ciencia, porque es un mecanismo de integración entre las categorías y no segregación. Palabras clave: Comunicación Pública de la Ciencia. Experto. Company.

Submissão: 12-10-2016

Decisão editorial: 19-9-2018 


\section{Introdução}

A ciência é um padrão de racionalidade que tem condições de explicar o funcionamento do universo, das experiências e desenvolver mecanismos de controle, proporcionando o desenvolvimento tecnológico. Assim, a tecnologia deve auxiliar no autoentendimento da sociedade e somente no seu desenvolvimento, o que faz surgir desenvolvimentos teóricos e tecnológicos com temas de preocupação social. Porém, a sociedade é capaz de questionar a ciência e os cientistas como tomadores de decisão, surgindo o tema da demarcação: o questionamento do que é científico e do que não é.

Desse modo, se a ciência explica os fenômenos e desenvolve tecnologia, que interfere direta ou indiretamente na sociedade, logo se faz necessária a comunicação pública da ciência, na qual há a preocupação em se transmitir conhecimento científico a todo público, inclusive ao público leigo.

Para Popper (2001), as teorias científicas podem ser testadas por "falseabilidade" dos enunciados. Entretanto, a ciência deve manter a imparcialidade e neutralidade relacionadas à aceitação social dos valores que "validam uma teoria como científica". Para Kuhn (1995), a comunidade científica estabelece os critérios de neutralidade, imparcialidade e 
objetividade da ciência por meio dos paradigmas. Já Lacey (1998), discorda de Kuhn devido à existência de diferentes cenários institucionais e valores sociais. O que se trata de uma versão mais coerente, uma vez que culturas diferentes promovem estruturas institucionais diferentes (SCHOR, 2007).

Se por "público leigo" entendemos a totalidade da população menos os cientistas, esse público compreende toda a gama da alfabetização científica, desde os completamente jejunos e/ou avessos à ciência, os medianamente interessados, os alfabetizados cientificamente, até os próprios cientistas de especialidade diferente da divulgada (EPSTEIN, p. 23, 2012).

Para Kreimer (2007), existem formas de estimular a comunicação da ciência por meio do engajamento e da popularização da ciência. A primeira é de o Estado estimular a implementação de instrumentos e políticas e proporcionar uma participação ativa quanto à aplicação dos instrumentos e orientar as instituições. A segunda é com as comunidades acadêmicas (exatas e naturais) para pensar no papel do conhecimento produzido. Para que eles legitimem os estudos de ciência como um produto de "pares", assim como mencionou Bloor (1991), Solla Price (1963) e Bourdieu (2008), que falavam de uma "ciência da ciência". A terceira é nas ciências sociais, para pensar como um "subcampo de produção conhecimento social".

As ciências sociais enfrentam muitas dificuldades para serem citadas, para serem avaliadas por órgãos de pesquisa. A quarta é o respeito de outros atores da sociedade tanto com a democratização do conhecimento, como com estimular a participação que rompa com a cristalização "experts-Estado". 
A expertise é o conhecimento que os atores (indivíduo ou comunidade) possuem, seja por teoria ou pela prática. O conhecimento teórico (expertise especializada) é certificado por políticas científicas (negociações), que defendem a legitimidade de determinado campo (COLLINS; EVANS, 2002), onde cientistas são dotados de um capital científico, que simboliza crédito e confiança no conhecimento e reconhecimento da sua formação (BOURDIEU, 2008).

O objetivo desta pesquisa é analisar as relações das expertises na comunicação pública da ciência, facilitando a promoção de ciência. A partir da comunicação da ciência e das relações das expertises, pode ser possível propagar o conhecimento restrito tanto à ciência, como a determinadas culturas, que possam possuir expertise ubíqua.

Nesse sentido, o percurso metodológico do estudo compreende o levantamento e análise bibliográfica referente à temática aliados à pesquisa empírica em um boletim eletrônico do Instituto Federal de Educação, Ciência e Tecnologia de São Paulo (IFSP), como sendo esse um instrumento de comunicação pública da ciência, apresentando uma "comunicação de duas vias".

\section{A comunicação pública da ciência}

A comunicação pública da ciência pode se estabelecer de duas formas: de um lado o modelo de "via de mão única" ou standard, verticalizado, em que se estabelece uma relação de poder do emissor (especialista) sobre o receptor (público); de outro lado está a "comunicação em duas vias", onde o público é ativo e integrado ao processo, dialogando e compartilhando da comunicação (KNORR-CETINA, 1999; COSTA et al., 2010). 
Costa et al. (2010) afirmam que o modelo que tende a prevalecer é o unidirecional ou de "via de mão única", em que os cientistas são denominados como os detentores do conhecimento, e o público como marginal aos fatos científicos. Porém, afirmam que dentro dessa tendência, existem mais três modelos de comunicação: o primeiro, em que o receptor não é totalmente deficitário, pois detém os conhecimentos conforme fatores sociais e psicológicos da sua realidade; o segundo é a tendência bilateral, em que os conhecimentos públicos locais podem ter a mesma importância que o conhecimento científico, e o terceiro é o da participação pública, em que o público participa tal qual os cientistas.

Já Cloître e Shinn (1985) apud Bucchi (2004) classificam essa comunicação em quatro níveis, os quais são: Intraespecífica, Interespecífica, Pedagógico e Popular. No nível Intraespecialista, especialistas da mesma ciência compartilham de dados em revistas específicas; no nível Interespecialista, a relação se dá por meio da multidisciplinaridade, com especialistas de áreas díspares; no nível Pedagógico, a ciência está consolidada em forma de paradigma e se aplica de forma cumulativa; já no nível Popular, se utilizam metáforas para aproximar leigos do conteúdo científico.

Ambos os autores visualizam um cenário de dominação do conhecimento científico sobre um público leigo. Entretanto, apresentam modelos ou níveis de comunicação que podem ser utilizados como ferramentas para se alfabetizar com ciência, de forma que o público leigo possa, além de receber a informação, participar da ciência, não ficando marginalizado.

Os modelos de marginalização da participação pública na ciência vêm sendo criticados, pois neles 
se ignora a capacidade intelectual e política do público e se priva o interesse de grupos dominantes e a influência de suas agendas de pesquisa (MARTIN, 2006). Entretanto, a popularização da ciência por não cientistas pode também distorcer informações.

Desse modo, um cientista pode simplificar a forma de se passar as informações para que as mesmas cheguem até o público de forma que se adeque a determinado contexto.

Assim, a compreensão pública da ciência pode interferir na forma como ela é feita, podendo servir para conscientizar a população sobre a necessidade de se pesquisar ou até mesmo acerca da necessidade de se desenvolver determinada tecnologia. Entretanto, desse modo os cientistas ainda detêm o modelo dominante, podendo ignorar o conhecimento tradicional não científico (SISMONDO, 2010).

Na forma tradicional de comunicação da ciência, os jornalistas científicos são mediadores da informação para os leigos. Contudo, os cientistas estão propensos a distorções e sensacionalismos, ou seja, a mídia pode ser vista como um "espelho sujo", que não reflete os fatos científicos (BUCCHI, 2004). Isso pode ocorrer devido ao distanciamento das pesquisas e falta de compreensão dos procedimentos que acontecem "dentro do laboratório".

Aprender ciência significa aprender a falar sobre ciência com linguagem própria e que se faça compreender, o que caracteriza uma enculturação na comunidade científica. As revistas científicas trazem a linguagem técnica das ciências, entretanto, essa forma de comunicação é vista como de difícil compreensão, o que aliena comunidades leigas (BARAMTSABARI; LEWENSTEIN, 2012). 
Isso ocorre porque a ciência possui seu método científico e uma linguagem comum, o que cria fronteiras sociais e culturais que podem ser prejudiciais no sentido de distanciá-la de outras culturas (BAUCHPIES; CROISSANT; RESTIVO, 2006). Um exemplo que deve ser levado em consideração do objetivo de comunicação pública da ciência é a revista de ciência popular National Geographic, que é a mais conhecida entre leigos e que traz uma linguagem menos complexa (STEKOLSCHIK et al., 2010).

Todavia, essa revista não faz parte de uma cultura de massa, pois os leigos que têm acesso a essa revista são leigos dentro de determinadas especialidades ou expertises, ou seja, conforme Bucchi (2004), de um nível interespecialista ou multidisciplinar. Não se trata, assim, da popularização da ciência, onde há a intenção de veicular as informações como cultura de massa, utilizando vocabulário simples, cercado por metáforas ou analogias feitas por jornalistas.

Nesse sentido, Baram-Tsabari e Lewenstein (2012) propõem um modelo para facilitar a comunicação pública da ciência sem que haja interpretações errôneas por parte dos comunicadores da ciência. Assim, estabeleceram critérios, que consistem em: 1. Preparação: estabelecimento das relações entre o cientista e o jornalista, que envolve desde a escolha da mídia, o conhecimento do público-alvo e a forma de transmitir a mensagem; 2. Conteúdo da mensagem: mensagens concisas, claras e sem excesso de informação, foco nos principais pontos; 3. Estilo da mensagem: uso de analogias, metáforas, figuras, gráficos, animações e vídeos; 4. Linguagem da mensagem: uso de palavras simples, frases curtas e sem o uso de jargões.

O referido modelo seria útil para que não houvesse distorções na comunicação da ciência, pois o 
jornalista conheceria melhor o que de fato deve ser transmitido e como deve ser feito. Tal parceria seria na verdade o elo entre especialista e público de forma mais imparcial, porém, mais figurativa.

Sob outra ótica, Cuevas (2008) propõe um "modelo democrático", que Martin (2006) chama de "ciência para o povo" (comunicação da ciência) e "ciência pelo povo" (participação pública), com o reconhecimento de múltiplos conhecimentos entre público e cientistas para a tomada de decisão.

Deste modo, a ciência e a tecnologia deixariam de ser objeto de dominação, sendo a comunicação o elo entre cientistas e público. Mas o que acontece nas democracias contemporâneas é que as tomadas de decisão acabam por ficar em mãos de especialistas (experts) e políticos e também pelo comodismo dos cidadãos em não exercerem seus reais papéis democráticos. A comunicação pública da ciência, além de propiciar o conhecimento, tenderia a estimular a vocação científica (STEKOLSCHIK et al., 2010), além de agregar à expertise de determinada sociedade.

Não seria uma tarefa fácil estimular a vocação cientifica, uma vez que isso demandaria um grande investimento nas ciências. Porém, para Epstein (p. 25, 2012) "erradicar o analfabetismo científico" seria um dos meios mais viáveis de se estimular e engajar a população nos usos da ciência e tecnologia sobre o meio em que se vive.

\section{As expertises}

Em geral, as expertises caracterizam o conhecimento de atores, sejam eles especialistas científicos ou público leigo. Existem diferenças até mesmo entre cientistas em razão das dessemelhanças das experti- 
ses dos campos científicos. Knorr-Cetina (1999) ressalta que entre o público leigo também se encontram peritos de campos científicos diferentes que são capazes de "conversar e negociar" sobre Ciência, Tecnologia e Sociedade (CTS).

As fronteiras entre os experts de diferentes expertises são construídas pelas instituições que os formam, não só por meio de graduações, mas também com valores.

Logo, num dado momento um cientista pode ser o expert, enquanto em outro, o leigo. Já o conhecimento empírico (expertise leiga) está pautado na experiência ou em uma tradição, muitas vezes com ausência de critérios para validá-los (COLLINS; EVANS, 2002). Entretanto, a aquisição da expertise ocorre por aprendizado, ou seja, um indivíduo que mantenha contato por certo período, com determinado conjunto de conhecimentos, tende a tornar-se um expert. "A aprendizagem envolve um período de interação intensiva com objetos do conhecimento bem como, com outras pessoas que têm supostamente dominado aqueles objetos" (CARR, p. 19, 2010), ou seja, devem aprender a se comunicar com familiaridade, além de dominar uma linguagem própria.

De acordo com Collins e Evans (2002), há diferentes tipos de expertises que podem ser combinadas na vida social para a tomada de decisões. Nesse sentido, para que ocorra essa relação, é necessário desenvolver uma linguagem que possibilite a compreensão dos experts ou que uma das partes dos experts aprenda a linguagem do outro, facilitando a comunicação na ausência de competência prática, o que recebe o nome de expertise de interação. 
Toda sociedade possui sua expertise, que por sua vez é "inerentemente interacional, porque envolve a participação de objetos, produtores e consumidores de conhecimento" (CARR, p. 18, 2010). Diferente da expertise leiga, em que o indivíduo ou comunidade possui um conhecimento empírico, o senso comum pode ser superficial, devido à falta de experiência e por estar relacionado a algum paradigma imposto pela cultura da sociedade, que para Santos (1989, p. 44) se reproduz espontaneamente e contribui para a "emancipação cultural e social".

Todavia, o senso comum pode variar conforme as relações sociais de uma sociedade, apresentandose menos desigual e menos ignorante. Para Collins e Evans (2010), esse conhecimento pode ser chamado de expertise ubíqua, em que as pessoas aprendem naturalmente e podem ser características de algumas sociedades e de outras não, por exemplo, a construção de diques pelos holandeses.

A partir dos conflitos entre conhecimento científico e senso comum, Santos (1989) propõe uma dupla ruptura epistemológica, que culminaria em uma transformação em que o senso comum seria esclarecido e a ciência teria uma visão prática.

Dessa forma, por sua vez, haveria a comunicação da ciência por parte dos cientistas, como KnorrCetina (1999) afirma, que há um consenso nas sociedades ocidentais de que o conhecimento de muitos indivíduos é influenciado pelas informações e saberes produzidos por especialistas. Uma visão padrão de popularização da ciência, por meio da simplificação das representações científicas, como o que de certa forma já vem ocorrendo por intermédio de documentários e vídeos veiculados pela mídia. 
Guivant e Macnaghten (2011) sugerem a tomada de decisão a partir de uma relação entre o conhecimento especializado e a expertise leiga, com a indicação de fóruns para discussões para as tomadas de decisão. A intenção não seria a busca de um consenso, já que surgiriam controvérsias, mas sim melhorar as "precondições" para as ações políticas, porém essa situação seria utópica.

O consenso, como Joly e Kaufmann (2008), que sugerem para o engajamento político uma combinação da Teoria Ator Rede com a participação pública; Ottinger (2010) acredita que os cidadãos possuem capacidade de influenciar os cientistas por meio do monitoramento de seus trabalhos; Bickerstaff et al. (2010) falam da institucionalização do diálogo; Machnagten e Chilvers (2012) propõem a análise das preocupações do público, sendo a real preocupação não somente comunicar ao público, mas sim envolvêlo nas questões de governança. Leach et al. (2005) estabelecem uma relação dinâmica entre os contextos especializados globais e leigos e locais.

Essas propostas surgem devido à descrença na ciência e as falhas tecnológicas que foram proporcionadas. Dessa forma, Guivant e Macnaghten (2011) apresentam a crítica ao conhecimento especializado e a importância do conhecimento local.

\section{Percurso metodológico}

O estudo traz em seu percurso metodológico - levantamento e a análise bibliográfica, aliados à pesquisa empírica sumária em um boletim eletrônico do IFSP. Optou-se por uma abordagem exploratória. Neste sentido, Freitas et al. (2000) discorrem que as pesquisas exploratórias objetivam a familiarização do 
pesquisador com os arcabouços conceituais e com as abordagens anteriormente realizadas.

O levantamento e a análise bibliográfica foram feitos por meio de pesquisas realizadas em livros e periódicos especializados. Essa etapa, também denominada pesquisa bibliográfica, é fundamental e parte integrante de toda e qualquer pesquisa, Boccato aponta:

...a pesquisa bibliográfica busca a resolução de um problema (hipótese) por meio de referenciais teóricos publicados, analisando e discutindo as várias contribuições científicas. Esse tipo de pesquisa trará subsídios para o conhecimento sobre o que foi pesquisado, como e sob que enfoque e/ou perspectivas foi tratado o assunto apresentado na literatura científica (BOCCATO, 2006, p. 266).

Os autores Pizzani et al. (2012, p. 65) ratificam que os pesquisadores devem atentar para a importância de usar vocabulário controlado ao realizarem pesquisas bibliográficas em bases de dados, assim como fazer uso de estratégias de busca para combinar os termos da pesquisa e realizar as pesquisas em bases de dados confiáveis.

A pesquisa empírica foi realizada, de maneira sumária, em um boletim eletrônico do IFSP denominado "Você na Federal", uma publicação bimestral destinada aos discentes do IFSP, que traz como proposta compartilhar informações e experiências de ações de ensino-pesquisa-extensão dos campi do IFSP e do universo dos estudantes de forma clara e concisa (IFSP. COMUNICAÇAO, 2015).

A pesquisa empírica objetivou verificar os tipos de notícias veiculadas no boletim, público-alvo, equipe editorial e design do boletim. O IFSP é uma autarquia 
federal, originária das Escolas de Aprendizes e Artífices. Criada em 1909, passou por diversas reformulações, sendo a última em 2008, pela Lei n. 11.892, que instituiu a Rede Federal de Educação, Ciência e Tecnologia (BRASIL, 2008).

Os Institutos Federais, como popularmente conhecimentos, estão representados em todos os Estados brasileiros. Com a última reformulação, O IFSP passou a destinar $50 \%$ das vagas para os cursos técnicos e, no mínimo, $20 \%$ das vagas para os cursos de licenciatura, sobretudo nas áreas de Ciências e da Matemática. Paralelamente, continua ofertando cursos de formação inicial e continuada, tecnologias, engenharias e pós-graduação (IFSP. HISTÓRICO, 2015).

O IFSP é organizado em estrutura multicampi e possui aproximadamente 24 mil discentes matriculados nos 37 campi espalhados pelo Estado (IFSP. HISTÓRICO, 2015).

O Estatuto, instrumento normativo de controle, referendado pela Resolução $n^{\circ}$. 1, de 31 de agosto de 2009, do Conselho Superior e alterado pelas Resolução $n^{\circ}$. 872, de 4 de junho de 2013 , e pela Resolução $n^{\circ}$. 8, de 4 de fevereiro de 2014, traz como finalidades e características em seu $5^{\circ}$. Artigo:

I. ofertar educação profissional e tecnológica, em todos os seus níveis e modalidades, formando e qualificando cidadãos com vistas à atuação profissional nos diversos setores da economia, com ênfase no desenvolvimento socioeconômico local, regional e nacional; II. desenvolver a educação profissional e tecnológica como processo educativo e investigativo de geração e adaptação de soluções técnicas e tecnológicas às demandas sociais e peculiaridades regionais;

III. promover a integração e a verticalização da educação básica à educação profissional e educação 
superior, otimizando a infraestrutura física, os quadros de pessoal e os recursos de gestão;

IV. orientar sua oferta formativa em benefício da consolidação e do fortalecimento dos arranjos produtivos, sociais e culturais locais, identificados com base no mapeamento das potencialidades de desenvolvimento socioeconômico e cultural no âmbito de atuação do IFSP;

V. constituir-se em centro de excelência na oferta do ensino de Ciências, em geral, e de Ciências Aplicadas, em particular, estimulando o desenvolvimento de espírito crítico, voltado à investigação empírica (IFSP. ESTATUTO, 2009).

Dessa maneira, observa-se que a investigação empírica é uma das finalidades da instituição e esta deve ser repassada à sociedade, de maneira que a comunicação e a divulgação não só científica sejam feitas de forma clara e que a sociedade possa interagir e participar com os avanços científicos e tecnológicos da instituição, ou seja, a "comunicação em duas vias" como apontam Knorr-Cetina (1999) e Costa et al. (2010).

Foi feita a verificação, durante o mês de janeiro de 2016, no portal IFSP' sobre a existência de produtos ou serviços que possam ser considerados instrumentos de popularização e divulgação da ciência.

O IFSP tem uma Assessoria de Comunicação que é responsável pela comunicação institucional da Reitoria, coordenando as ações comunicativas de todos os campi.

A Assessoria de Comunicação conta com um assessor e três jornalistas, disponibiliza manuais infor-

Maiores informações sobre o IFSP, acessar o portal: www.ifsp. $\underline{\text { edu.br }}$ 
mativos, orientações quanto à realização de eventos e divulgações institucionais.

O departamento também coordena e agrupa os produtos e serviços de divulgações científicas e não científicas da instituição. Cada campus possui um servidor que responde pela comunicação no campus e faz a intermediação entre o campus e a Assessoria.

Entre os produtos e serviços de comunicação institucionais, tem-se: revistas impressas e eletrônicas; boletins eletrônicos (um deles é o "Você na Federal"); manuais de procedimentos institucionais, vídeos institucionais, notícias midiáticas, entre outros. A Figura 1 ilustra o boletim "Você na Federal", apresentando um dos fascículos.

Figura 1 - Boletim "Você na Federal"

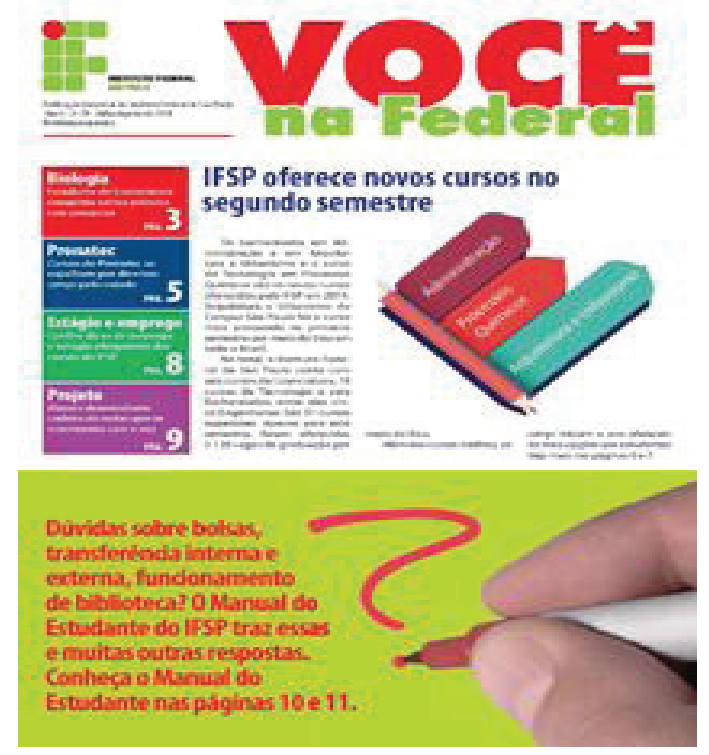

Fonte: Boletim "Você na Federal" (2015). 
Dos produtos e serviços disponíveis institucionais, o boletim "Você na Federal" compõe o recorte investigativo nesta pesquisa. O boletim é um serviço instituído com periodicidade bimestral, direcionado aos discentes do IFSP. As edições eletrônicas estão acessíveis no portal para download desde 2010, porém, a última edição disponível corresponde aos meses de julho e agosto de 2014.

Conforme informações da Assessoria de Comunicação do IFSP, a publicação está temporariamente suspensa. Portanto, constam 29 boletins disponíveis eletronicamente, que abordam em linguagem clara, diferentes assuntos em seus expedientes. Citam-se alguns: pesquisas científicas desenvolvidas pelos campi; exposições, feiras e eventos; entrevistas com docentes; discentes e egressos da instituição; divulgação de processos seletivos; convênios institucionais; editais de fomento; entre outros.

Na análise do material, compreendeu-se o boletim como um meio de comunicação de duas vias, pois o produto em si foi pensado e elaborado para os discentes. Estes se situam como protagonistas da publicação, de maneira que foram elaboradas matérias, entrevistas, posaram para fotos e mais do que isso, podiam compreender do início ao fim os assuntos abordados, pois peritos dos mais diferentes campos científicos decodificavam e traduziam suas expertises, por intermédio dos jornalistas, para que estas fossem compreendidas pelos discentes e vice-versa.

Na análise do layout do boletim, identificou-se um design atrativo e colorido, para chamar a atenção dos alunos para a leitura. Nesse sentido, considera-se o público do boletim como um público ativo e integrado, dialogando e compartilhando informações. 
Salienta-se que a figura do jornalista como mediador nesse processo foi fundamental, mas se ressalta que o perito especializado deve trabalhar com o jornalista, para que a linguagem a ser tratada com - discente seja a mais clara possível, e o contrário também se faz necessário.

Compreende-se que o boletim se apresenta como uma ferramenta de popularização da ciência, tornando-se importante para a instituição e para toda a comunidade como uma ferramenta de aproximação da comunidade acadêmica com os produtos $e$ serviços elaborados e desenvolvidos pelo IFSP.

\section{Discussões}

O perito atua na certificação dos usos e aplicações por meio de ensaios químicos, físicos e mecânicos que possam afirmar ou contestar o senso comum, ocorrendo, nesse caso, a dupla ruptura epistemológica proposta por Santos (1989), em que os cientistas testam o conhecimento leigo e facilitam a prática por parte dos leigos.

Nessas condições, a ocorrência da dupla ruptura proposta por Santos (1989) apresenta maior dificuldade, porque o senso comum não permite um diálogo fundamentado na prática, uma vez que a prática é pouco perpetrada, além das ocorrências esparsas. Entretanto, a comunicação pública da ciência, ancorada no fato de que o conhecimento dos indivíduos ocidentais é influenciado pelos saberes dos cientistas, assim Knorr-Cetina (1999) pode auxiliar na mudança da concepção do senso comum. Ademais, a comunicação pública da ciência pode ajudar na promoção e divulgação do conhecimento, favorecendo o rompimento de paradigmas. 
A comunicação pública da ciência é necessária, porém apresenta grandes riscos, porque pode ser feita entre o próprio cientista e o público, ou por intermédio de um jornalista. Na comunicação entre o cientista e um público leigo, no sentido da popularização da ciência, o risco consiste em transmitir a informação de forma compreensível por meio de um vocabulário mais simplificado e do uso de metáforas ou analogias. Isso porque a expertise dos cientistas está relacionada ao campo científico ao qual pertencem, que valida o conhecimento e teorias.

Enquanto a expertise leiga faz parte do universo de uma sociedade que vive sob a ótica de paradigmas ou práticas, a expertise ubíqua, porém, pode variar conforme a cultura de uma sociedade, mesmo que seja relacionada ao fato de se desenvolver naturalmente nos indivíduos. Também há a diferença entre as expertises científicas, que não requerem uma simplificação tão profunda devido aos conhecimentos prévios em termos de vocabulário.

Outro risco pode haver quando a comunicação da ciência ocorre por intermédio de um jornalista. Este deve estar totalmente inserido e familiarizado com o assunto que será transmitido, uma vez que ele comunicará o que ele acredita ser a real informação passada ao público pelo cientista. Quando o conhecimento chegar até o público leigo que se destina, ele trará as interpretações, metáforas e analogias sob sua ótica, que em princípio deve ser imparcial.

Caso a transmissão do conhecimento não seja fiel, pode ocorrer falsa compreensão da ciência por meio do sensacionalismo, não havendo assim a alfabetização do público leigo. Mas havendo a compreensão, é possível que se obtenha a devolutiva 
do público leigo, seja por intermédio de mais questionamentos, seja por meio de possibilidades em se ampliar o conhecimento científico em parceria com o conhecimento ubíquo de determinada sociedade.

Visto que a comunicação e a intermediação do boletim "Você na Federal" eram feitas pela Assessoria da Comunicação da Reitoria do IFSP, composta em sua maioria por jornalistas, percebeu-se o cuidado dos mesmos em laborar com uma linguagem passivel de entendimento e compreensão tanto para os experts, quanto para os leigos, ou seja, um equilíbrio na relação entre as comunidades, equilíbrio esse dissertado por Santos (1989).

Vale ressaltar que as informações disponíveis no boletim eram fluidas, permeavam teores de alta complexidade, como desenvolvimento de produtos ou processos de inovação, até divulgações corriqueiras de atividades desenvolvidas nos diversos campi. Assim, a linguagem adotada no boletim deveria ser amplamente acessível para atingir um maior número de interessados, sendo em sua maior parte compreendido por alunos.

O estudo propôs analisar as relações das expertises na comunicação pública da ciência, facilitando a promoção de ciência. Isto posto, pode-se verificar, ancorado no referencial teórico investigado e na análise estrutural feita que: o boletim, com seu conteúdo voltado para uma comunidade leiga, popularizava os projetos desenvolvidos pelos campi, assim como dava grande visibilidade a toda comunidade do IFSP: docentes, discentes e técnico-administrativos.

Compreende-se que a partir da comunicação da ciência e das relações das expertises pode ser possível propagar o conhecimento restrito tanto à ciência, 
como a determinadas culturas, que possam possuir expertise ubíqua. Nesse sentido, em um contexto escolar, produtos como o boletim "Você na Federal" se traduzem em formar práticas de baixo custo de popularização e divulgação da ciência.

Knorr-Cetina (1999) discorre que a comunicação pública da ciência fortalece a promoção e divulgação do conhecimento, auxiliando no rompimento de paradigmas, porém, os riscos são iminentes, pois a comunicação deveria ser compreensível e confiável.

A experiência com a análise da estrutura organizacional, visual, assim como do conteúdo do boletim "Você na Federal", se traduziu em uma situação positiva, pois se pôde verificar que as expertises especialistas e leigas trabalharam juntas, existindo interação. Ainda que haja fatores de risco, a publicação se traduz como benéfica, pois abre espaço para a comunicação de divulgação científica, o debate de ideias e a troca de experiências, não havendo a preocupação em ressaltar uma ou outra expertise, e sim somando conhecimentos e experiências para todos os envolvidos do IFSP e da sociedade.

Desse modo, propõe-se que o boletim "Você na Federal" volte a circular, pois se trata de uma experiência de sucesso que merece ser retomada, visto que o IFSP tem como um de seus objetivos "desenvolver a educação profissional e tecnológica como processo educativo e investigativo de geração e adaptação de soluções técnicas e tecnológicas às demandas sociais e peculiaridades regionais" (IFSP. ESTATUTO, 2009).

Analisando a conjuntura de que o IFSP oferta cursos técnicos conglomerados com o ensino médio, em que há uma parcela considerável de adolescentes, o 
boletim, com seu layout arrojado e com uma linguagem simples, facilitará a popularização da ciência para este público em especial.

\section{Considerações finais}

A dupla ruptura epistemológica proposta por Santos (1989) seria o equilíbrio da relação entre as expertises especializada e leiga, entretanto, romper com as fronteiras existentes entre elas pode não ser uma tarefa fácil, uma vez que as mesmas são consideradas opostas. Logo, como sugere Santos (p. 41, 1989), "a oposição ciência/senso comum não pode equivaler a uma oposição luz/trevas", uma vez que o preconceito não é algo particular do senso comum, e a ciência vem reconhecendo que não é fácil se livrar deles. Entretanto, os cientistas devem atentar para não se acomodarem com informações vulgares e preconceitos que possam omitir o conhecimento.

Assim, com a alfabetização sobre as diversas áreas do conhecimento seria possível estabelecer a comunicação em todos os níveis propostos por Cloître e Shinn (1985) apud Bucchi (2004), Cuevas (2008) e Martin (2006), satisfazendo todos os níveis intelectuais. A participação pública poderia se dar pelo diálogo com comunidades e sociedades que dominam determinados conhecimentos, aliando expertises especializadas dos cientistas e expertises ubíquas.

Dessa maneira, a experiência com o produto "Você na Federal" se traduz em uma prática positiva, pois as expertises especialistas e leigas trabalham juntas, existindo interação. Ainda que haja fatores de risco, a publicação se traduz como benéfica, pois abre espaço para a comunicação de divulgação científica, o debate de ideias e a troca de experiên- 
cias, não ressaltando uma ou outra expertise, e sim somando conhecimentos e experiências para todos os envolvidos do IFSP e a sociedade.

Portanto, seria interessante que o boletim "Você na Federal" voltasse a circular, pois essa foi uma experiência de sucesso que merece ser retomada. A veiculação do referido boletim poderia se dar via correio eletrônico dos alunos e servidores do IFSP, além do armazenamento do material no repositório institucional do IFSP.

Compreende-se que o boletim se apresenta como uma ferramenta que desperta o interesse da comunidade em veicular seus projetos desenvolvidos, não necessitando ser um expert em uma ou em outra área do conhecimento apenas.

Destaca-se que o artigo suscita discussões e reflexões iniciais, havendo um campo vasto de análises e convergências, que poderão ser exploradas em demais pesquisas e publicações futuras.

\section{Referências}

BARAM-TSABARI, A.; LEWENSTEIN, B. V. An Instrument for Assessing

Scientists' Written Skills in Public Communication of Science. Science Communication, 2012, p. 56-85. Disponível em:

http://scx-sagepub-com.ez31.periodicos.capes.gov.br/content/35/1/56.full.pdf+html. Acesso em 19 set. 2016.

BAUCHPIES, W. K.; CROISSANT, J.; RESTIVO S. Science, technology and society: a sociological approach. Blackwell Publishing, 2006.

BICKERSTAFF, K., LORENZONI, I., JONES, M.; PIDGEON, N. Locating Scientific Citizenship, The Institutional Contexts and Cultures of Public Engagement. Science, Technology and Human Values, 35, p. 474-50, 2010. Disponível em: <http://sth.sagepub.com/content/early/2010/03/03/0162243909345835>. Acesso em: 16 set. 2016.

COLLINS, H.; EVANS, R. Repensando a expertise. Tradução SILVA, Igor Antonio Lourenço. Belo Horizonte: Frabrefactum, 2010. 


\section{Cintia Almeida da Silva Santos, Samara Pereira Tedeschi, Wanda Aparecida Machado Hoffmann}

COSTA, A. R. F.; SOUSA, C. M.; MAZZOCO, F. J. Modelos de comunicação pública da ciência: agenda para um debate teórico-prático. Conexão, Comunicação e Cultura. Caxias do Sul, v. 9, n. 18, p. 149158, 2010. Acesso em: 16 set. 2016.

CUEVAS, A. Conocimiento cientííco, ciudadanía y democracia. Rev. iberoam. cienc. tecnol. soc. [on-line], v. 4, n. 10, p. 67-83, 2008. Disponível em: http://www.scielo.org.ar/pdf/cts/v4n10/v4n10a06.pdf. Acesso em 16 set. 2016.

EPSTEIN, I. Comunicação da ciência: rumo a uma teoria da divulgação científica. Organicom, v. 9, n. 16-17, p. 20-38, 2012. Disponível em:

http://www.revistaorganicom.org.br/sistema/index.php/organicom/ article/viewFile/513/42. Acesso em 25 abr. 2016.

FREITAS, H.; Oliveira, M.; Saccol, A. Z.; Moscarola, J. O método de pesquisa de survey. Revista de Administração, v. 35, n. 3, p. 105-112, 2000. Disponível em: <http://www.ufrgs.br/gianti/files/artigos/2000/2000_092_RAUSP.PDF>. Acesso em: 9 jan. 2016.

GUIVANT, J. S.; MACNAGHTEN, P. O mito do consenso: uma perspective comparativa sobre governança tecnológica. Ambiente \& Sociedade, v. 14, n. 2, p. 89-104, 2011 . Disponível em: http://www.scielo.br/ scielo.php?script=sci_arttext\&pid=S1414-753X201 1000200007 . Acesso em: 2 mai. 2016.

IFSP. Comunicação. Publicações, 2015. Disponível e: <http://www. ifsp.edu.br/index.php/comunicacao/publicacoes/voce-na-federal. html>. Acesso em: 13 jan. 2016.

IFSP. Histórico, 2015. Disponível em: <http://www.ifsp.edu.br/index. php/instituicao/ifsp.html>. Acesso em: 13 jan. 2016.

JOLY, P. B.; KAUFMANN, A. Lost in translation? The need for 'upstream engagement' with nanotechnology on trial, Science as Culture, $v$. 17 , n. 3, p. 225-247, 2008.

KNORR-CETINA, K. A. A comunicação da ciência. In: GIL, F. A ciência tal como se faz. Lisboa: João Sá da Costa, 1999.

KREIMER, P. Estudios sociales de la ciencia e la tecnología en la America Latina: para que y para quien. Redes, v. 13, n. 26, p. 55-64, 2007. 
KUHN, T. S. A estrutura das revoluções científicas, 3. ed. São Paulo: Perspectiva, 1995.

LACEY, H. Valores e atividade científica. São Paulo: Discurso Editorial/ Fapesp, 1998.

LEACH, M.; SCOONES, I.; WYNNE, B. Science and Citizens. Globalization and the challenge of engagement. London: Zed Books, 2005.

MACNAGHTEN, P.; GUIVANT, J. Converging citizens? nanotechnology and the political imaginary of public engagement in Brazil and the United Kingdom, Public Understanding of Science, v. 20, n. 2, p. 207-220, 2010. Disponível em: http://pus.sagepub.com/content/early/2010/10/02/0963662510379084. Acesso em 2 mai. 2016.

MARTIN, B. Strategies for Alternative Science. In: S. Frickel and K. Moore, (orgs.), The New Political Sociology of Science: Institutions, Networks, and Power. Madison: University of Wisconsin Press, 272-98, 2006. Disponível em: http://www.uow.edu.au/ bmartin/ pubs/06Frickel.html. Acesso em 17 set. 2016.

OTTINGER, G. Buckets of resistance, standards and the effectiveness of citizen science. Science, Technology and Human Values, v. 35, n. 2, p. 244-270, 2010. Disponível em: <http://sth.sagepub.com/content/35/2/244.abstract>. Acesso em: 3 mai. 2016.

PIZZANI, L. et al. (2012). A arte da pesquisa bibliográfica na busca do conhecimento. Rev. Dig. Bibl. Ci. Inf., Campinas, v. 10, n. 1, p. 53-66, jul./dez. ISSN 1678-765X. Disponível em: <http://www.sbu.unicamp.br/ seer/ojs/index.php>. Disponível em: 9 jan. 2016.

POPPER, K. A lógica da pesquisa científica. São Paulo: Cultrix, 2001.

SANTOS, B. S. Introdução a uma ciência pós-moderna. Rio de Janeiro: Graal, 1989.

SCHOR, T. Reflexões sobre a imbricação entre ciência, tecnologia e sociedade. Scientiae Studia, São Paulo, v. 5, n. 3, p. 337-67, 2007. Disponível em: <http://www.revistas.usp.br/ss/article/viewFile/11115/12883>. Acesso em: 18 abr. 2016.

SISMONDO, S. An introduction to science and technology studies, 2. ed., p. 168-188. Willwey-Blackwell, 2010. 


\section{Cintia Almeida da Silva Santos, Samara Pereira Tedeschi, Wanda Aparecida Machado Hoffmann}

SOLLA PRICE, D. J. Little science, big science. Nova York, Columbia: University Press. 1963.

STEKOLSCHIK, G.; DRAGHI, C.; ADASZKO, D.; GALLARDO, S. Does the public communication of science influence scientific vocation? Results of a national survey. Public Understanding of Science, 2010, p. 625-637. Disponível em: <http://pus-sagepub-com.ez31.periodicos. capes.gov.br/content/19/5/625.full.pdf+html>. Acesso em 19 set. 2016.

\section{Cintia Almeida da Silva Santos Correio}

ORCID iDhttp://orcid,org/0000-0002-1832-3751

Universidade Federal de São Carlos (UFSCar)

Instituto Federal de São Paulo

Bibliotecária-Documentalista do Instituto Federal de São Carlos

Doutoranda do Programa de Pós-Graduação em Ciência, Tecnologia e Sociedade da Universidade Federal de São Carlos

Pesquisadora do Núcleo de Informação em Ciência, Tecnologia, Inovação e Sociedade da UFSCar.

Link para o lattes: http://lattes.cnpq.br/2599706906177671

\section{Samara Pereira Tedeschi Correio}

Universidade Federal de São Carlos

Doutoranda em Ciência, Tecnologia e Sociedade pela Universidade Federal de São Carlos (UFSCar).

Pesquisadora do Núcleo de Informação em Ciência, Tecnologia, Inovação e Sociedade da UFSCar.

Link para o lattes: http://lattes.cnpq.br/9369668064115028

Wanda Aparecida Machado Hoffmann Correio Universidade Federal de São Carlos

Professora Associada da Universidade Federal de São Carlos (UFSCar), vinculada ao Departamento de Ciência da Informação. Diretora do Centro de Educação e Ciências Humanas da UFSCar. Professora Permanente do Programa de Pós-Graduação em Ciência, Tecnologia e Sociedade e Professora Colaboradora do Programa de Pós-Graduação em Ciência e Engenharia de Materiais da UFSCar. Pesquisadora do Núcleo de Informação em Ciência, Tecnologia, Inovação e Sociedade, e do Núcleo de Informação Tecnológica em Materiais da UFSCar. Pós-Doutorado em conformação a quente (1997) na UFSCar. Pós-Doutorado em prospecção de informação tecnológica (2001) na UFSCar.

Link para o lattes: http://lattes.cnpq.br/7609135667093837 